\title{
ASESMEN ALIRAN KRITIS SISTEM PENGELOLAAN SAMPAH PERKOTAAN DI TPA SAMPAH
}

\author{
Bismi Annisa ${ }^{1}$ \\ ${ }^{1}$ Teknik Sipil Manajemen Sumber Daya Air dan Lingkungan, Fakultas Teknik, Universitas Islam Riau, \\ Pekanbaru.Email:annisa.bismi@gmail.com; bismi.annisa@eng.uir.ac.id
}

\begin{abstract}
Capacities of Cipayung landfill (final processing) has exceeded capacity. The composition of organic waste is the most dominant waste composition. This study aims to assess the critical flow of municipal solid waste management system in the Cipayung landfill thus be predicted or estimated improvement of waste management system in the landfill Cipayung. The research method using MFA STAN software for a period of one year beginning in 2017 until 2018. The results of this study are critical flow of waste management systems are in the process of sorting and empowerment are still done manually, so the impact on increasing the amount of garbage residue will be dumped in Cipayung landfill. Waste composition which includes the critical flow is organic waste, plastic, paper, glass and aluminum. All materials that are at a critical flow still can be empowered using mechanical sorting machines garbage. Management recommendation is to apply the technology of recycling, composting and RDF feedstock. The government should establish cooperation with the private sector to process waste into resources that extend the life of landfill serviceability. Through optimization scenario 1, the critical flow of waste management systems can be improved with a reduction of more than $50 \%$ of the waste to be dumped into landfill Cipayung.
\end{abstract}

Keywords: Composting, MFA STAN, Recycling, RDF, Waste Landfill

\begin{abstract}
Abstrak
Kapasitas tampung TPA (Tempat Pemrosesan Akhir) sampah Cipayung telah melebihi kapasitas. Komposisi sampah organik merupakan komposisi sampah paling dominan. Penelitian ini bertujuan untuk melakukan asesmen terhadap aliran kritis sistem pengelolaan sampah perkotaan di TPA Cipayung sehingga akan dapat diprediksi atau diestimasi perbaikan sistem pengelolaan sampah di TPA Cipayung. Metode penelitian menggunakan perangkat lunak (software) MFA STAN untuk periode satu tahun yang dimulai pada tahun 2017 hingga 2018. Hasil penelitian ini adalah aliran kritis sistem pengelolaan sampah terdapat pada proses pemilahan dan pemberdayaan yang masih secara manual, sehingga berdampak kepada besarnya sampah residu yang akan ditimbun di TPA sampah Cipayung. Komposisi sampah yang termasuk pada aliran kritis adalah sampah organik, plastik, kertas, kaca dan aluminium. Semua material yang berada pada aliran kritis masih dapat diberdayakan dengan menggunakan mesin mekanik pemilah sampah. Rekomendasi pengelolaannya adalah dengan menerapkan teknologi daur ulang, pengomposan dan bahan baku RDF. Pemerintah sebaiknya menjalin kerjasama dengan pihak swasta untuk mengolah sampah menjadi sumber daya sehingga memperpanjang umur layan TPA sampah. Melalui optimasi skenario 1, maka aliran kritis sistem pengelolaan sampah dapat diperbaiki dengan pengurangan lebih dari 50\% sampah yang akan ditimbun ke TPA sampah Cipayung.
\end{abstract}

Kata Kunci: Daur Ulang, MFA STAN, Pengomposan, RDF, TPA Sampah

\section{Pendahuluan}

TPA (Tempat Pemrosesan Akhir) sampah Cipayung merupakan satu-satunya TPA sampah di Kota Depok (gambar 1) yang digunakan sejak tahun 1984 berlokasi di Kelurahan Cipayung, Kecamatan Pancoran Mas. Sistem pengelolaan sampah di TPA sampah Cipayung adalah metode open dumping (1984-2002) dan setelah itu hingga saat ini menerapkan metode controlled landfill. Luas lahan TPA sampah Cipayung adalah 6,1 ha (1984-2002); 9,1 ha (2002-2007) dan penambahan terakhir area menjadi 11,2 ha (2008-saat ini). Kapasitas TPA Cipayung adalah $1.500 .00 \mathrm{~m}^{3}$. Jumlah sampah yang masuk ke 
TPA sampah Cipayung berkisar $800-1.200 \mathrm{~m}^{3} /$ hari atau rata-rata $1.000 \mathrm{~m}^{3} /$ hari. Luas lahan TPA sampah Cipayung mengalami masa kritis seiring pertambahan timbulan sampah yang memiliki laju pertambahan volume sebesar 10\% setiap tahunnya sejak tahun 2006-2009 (DKP Kota Depok, 2009). Menurut Kurniawati (2010), kapasitas tampung TPA (Tempat Pemrosesan Akhir) sampah Cipayung telah melebihi kapasitas dan komposisi sampah organik merupakan yang paling dominan. Untuk mendesain kota yang bebas sampah, teknologi yang diterapkan seharusnya sesuai dengan konteks pengurangan volume sampah di masa depan dan pemulihan (recovery) sumber daya dari sampah (Zaman et al., 2011). Penelitian ini bertujuan untuk melakukan asesmen terhadap aliran kritis sistem pengelolaan sampah perkotaan di TPA Cipayung sehingga akan dapat diprediksi atau diestimasi perbaikan sistem pengelolaan sampah di TPA Cipayung.

Berdasarkan Chang et al. (2009), Brunner dan Rechberger (2003) sebagaimana dikutip dari Pires et al. (2011), teknik analisa sistem telah diterapkan untuk menangani aliran sampah perkotaan melalui berbagai metodologi integratif dalam beberapa dekade terakhir. Misalnya adalah MFA. MFA (Material Flow Analysis)/analisa mengenai aliran material merupakan penilaian yang sistematis dari aliran dan stok material dalam sebuah sistem yang didefinisikan dalam ruang dan waktu. Perangkat lunak (software) yang dikembangkan dalam MFA, yaitu Sfinx (van der Voet, 1995), FLUX (Huijbregts, 2000), STAN (TU Wina, 2009), DYNFLOW (Elshkaki, 2000), Gabi (PE Internasional, 2006) dan Umberto (IFU, 2006).

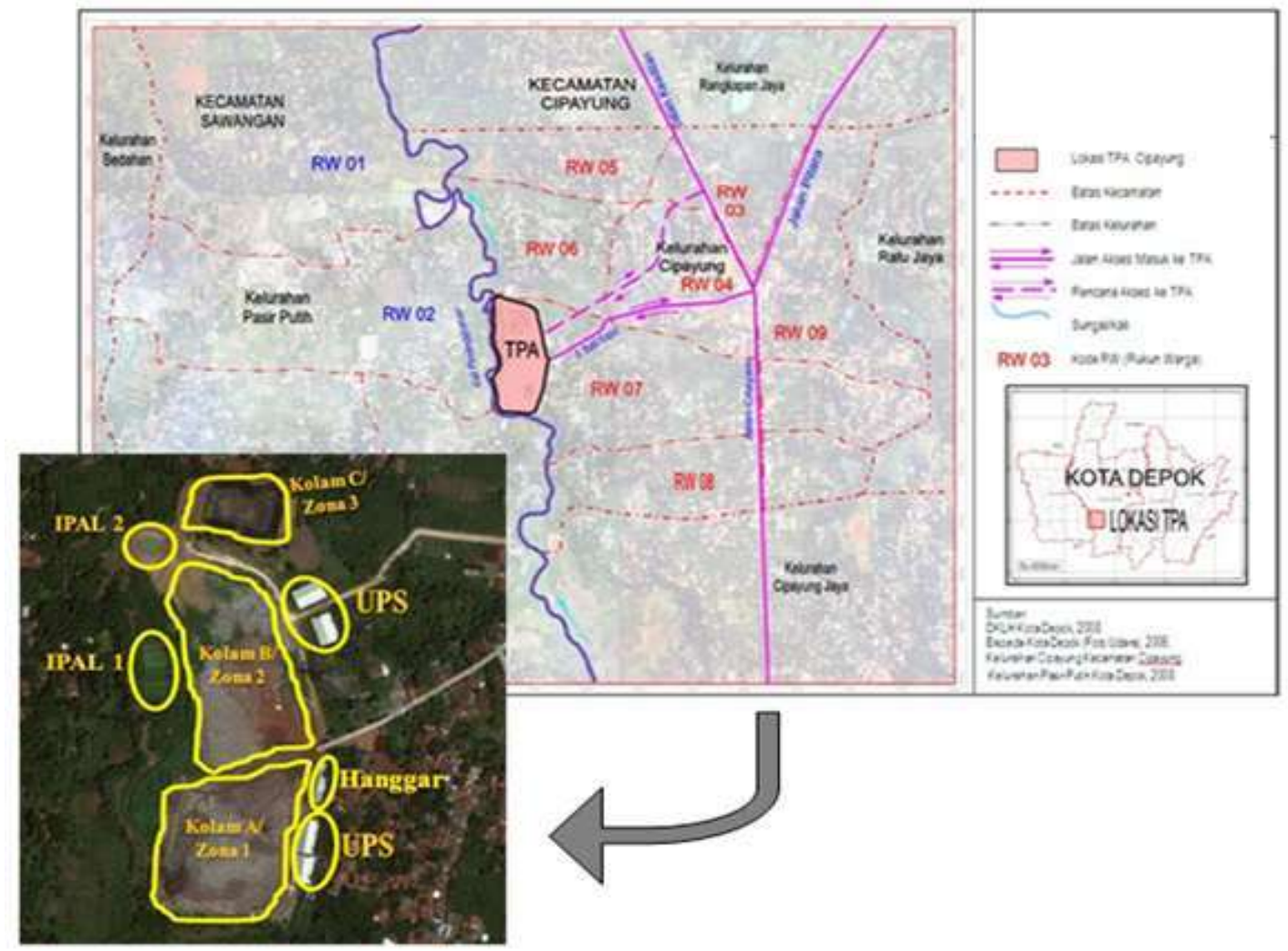

Gambar 1: Lokasi TPA Cipayung Depok

MFA yang dibentuk melalui model kesetimbangan massa STAN (short for subSTance flow ANalysis) versi 2.0 mengacu pada standar ÖNorm Austria 2096 (Cencic dan Rechberger, 2008) telah diterapkan untuk berbagai aplikasi bidang persampahan, misalnya seperti sistem pengomposan di rumah (home composting) (Andersen et al., 2011) serta berbagai skenario aliran material dan substansi (Cencic and Rechberger, 2008). Menurut Annisa (2013), diperlukan suatu kajian maupun penelitian mengenai aliran material maupun kesetimbangan massa di TPA sampah Cipayung sehingga akan dapat diketahui aliran kritisnya. Sampah kota Depok tidak seluruhnya diangkut ke TPA Cipayung, tingkat layan pengangkutan sampah kota Depok DKP Kota Depok (2011) adalah sebesar 33,34 \%. Model pelayanan sampah kota 
Depok secara rinci terdapat pada tabel 1, sedangkan skema laju timbulan sampah kota Depok dan laju pengangkutannya ke TPA Cipayung terlihat pada gambar 2.

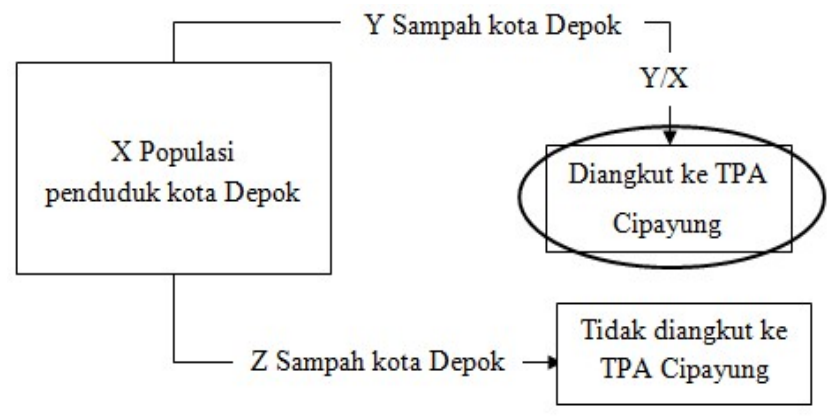

Gambar 2: Skema Laju Timbulan Sampah Kota Depok dan Laju Pengangkutan Sampah Kota Depok ke TPA Cipayung

Annisa (2016) menyatakan bahwa sampah di TPA Cipayung berpotensi untuk dapat dilakukan kegiatan recycle (daur ulang) dan recovery (pemulihan) material dan energi dari sampah, seperti potensi untuk daur ulang, kompos, dan energi berupa bahan bakar dari sampah (RDF/Refuse Derived Fuel). Untuk menerapkan kegiatan tersebut pada skala TPA agar tercapai pembangunan yang berkelanjutan, maka diperlukan suatu model mengenai aliran material sampah (MFA dengan STAN) berdasarkan skenario yang dibuat secara periodik untuk kegiatan reduksi sampah melalui kegiatan recycle dan recovery sampah. Dengan memodelkan dan mensimulasi skenario, maka akan tergambar dengan jelas dan terbaca dengan mudah mengenai aliran material di dalam sistem tersebut, misalnya berat sampah yang masuk ke sistem (input) serta aliran kritis di sistem (aliran/shankey yang paling lebar ukurannya).

Tabel 1: Model Pelayanan Sampah Kota Depok

\begin{tabular}{|c|l|l|}
\hline No & \multicolumn{1}{|c|}{ Sumber } & \multicolumn{1}{c|}{ Model pelayanan } \\
\hline 1 & $\begin{array}{l}\text { Permukiman } \\
\text { teratur }\end{array}$ & $\begin{array}{l}\text { Timbulan sampah yang berasal dari wadah sampah pada setiap rumah tangga dikumpulkan dengan } \\
\text { menggunakan gerobak sampah yang dikelola oleh Rukun Tetangga (RT) atau Rukun Warga (RW) } \\
\text { masing-masing., kemudian sampah tersebut dikumpulkan pada TPS atau transfer depo terdekat } \\
\text { untuk selanjutnya diangkut dengan truk menuju lokasi TPA. Kecuali Perum Jatijajar, truk sampah } \\
\text { datang langsung setiap 2 hari ke pemukiman lalu mengambil langsung sampah dari bak sampah } \\
\text { masing-masing rumah. Hal ini terjadi karena, dulu pernah ada TPS di dalam kompleks Jatijajar, } \\
\text { tetapi diprotes oleh warga karena menimbulkan bau. }\end{array}$ \\
\hline 2 & $\begin{array}{l}\text { Permukiman } \\
\text { tidak teratur }\end{array}$ & $\begin{array}{l}\text {-Cara individual: sampah yang dihasilkan biasanya dikelola sendiri dengan cara dibuang ke lubang } \\
\text { untuk selanjutnya dibakar atau dimanfaatkan sebagi kompos. Biasanya dilakukan oleh penduduk } \\
\text { yang memiliki lahan yang cukup luas. } \\
\text {-Cara komunal: sampah yang dihasilkan dari beberapa rumah/lokasi dikumpulkan pada lokasi TPS } \\
\text { untuk kemudian diangkut dengan truk ke lokasi TPA. Dilakukan pada lokasi perumahan tidak } \\
\text { teratur dengan tingkat kepadatan tinggi. }\end{array}$ \\
\hline 3 & Pertokoan & $\begin{array}{l}\text { Umunya sampah yang berasal dari wadah-wadah sampah yang berada di sekitar daerah pusat } \\
\text { perdagangan yang terletak pada jalur protokol, sampah dikumpulkan dari lokasi ke lokasi langsung } \\
\text { menggunakan truk dan selanjutnya diangkut menuju lokasi TPA. }\end{array}$ \\
\hline 4 & Pasar & $\begin{array}{l}\text { Sampah yang berasal dari wadah-wadah yang terdapat pada kios-kios pasar dikumpulkan dengan } \\
\text { gerobak untuk diangkut ke TPS atau kontainer yang disediakan pada lokasi pasar, kemudian } \\
\text { dipindahkan ke lokasi TPA dengan menggunakan truk. }\end{array}$ \\
\hline 5 & Jalan protokol & $\begin{array}{l}\text { Timbulan sampah yang berasal dari penyapuan jalan dan sampah yang berasal dari wadah sampah } \\
\text { di rumah atau bangunan yang berada di sekitar jalan protokol dikumpulkan dari lokasi ke lokasi. } \\
\text { Kemudian diangkut ke TPA dengan menggunakan truk. }\end{array}$ \\
\hline
\end{tabular}

Sumber: DKLH Kota Depok (2005) dan hasil observasi tim DKLH (2006), diolah oleh DKP Kota Depok (2011a)

\section{Metode}

\section{Lokasi dan waktu}

Lokasi penelitian adalah di TPA sampah Cipayung, Depok. Untuk lokasi pengambilan sampel penelitian adalah di TPA sampah Cipayung B selama 8 hari mengacu kepada SNI 19-3964-1994 (pagi dan sore hari). 


\section{Data Penelitian}

Data primer seperti pengukuran langsung di lapangan berupa sampel fisik sampah dan sampel pemulung adalah dari TPA sampah Cipayung yang sedang aktif digunakan, yakni di TPA Cipayung B. Sedangkan untuk uji laboratorium sampel sampah berupa karakteristik kimia, seperti analisa proksimat (kadar air, kadar volatil dan kadar abu) sampah yang mudah terbakar serta sampah organik dan analisa ultimat (kadar karbon dan nitrogen) sampah organik adalah di Laboratorium Teknik Penyehatan dan Lingkungan Universitas Indonesia.

\section{MFA dengan Perangkat Lunak (Software) STAN}

Data-data primer dan sekunder yang diperoleh akan dianalisa berdasarkan potensinya untuk diolah, yakni potensi untuk bahan baku daur ulang (recycle) serta recovery material (potensi untuk bahan baku daur ulang kompos) dan energi (potensi untuk bahan baku daur ulang dan bahan baku energi/RDF). Kemudian hasil perhitungan dan analisa diintegrasikan untuk membuat model MFA STAN berdasarkan penilaian dan modelisasi pada kondisi eksisting sistem pengelolaan sampah di TPA Cipayung serta merancang modelisasi untuk skenario upaya recycle dan recovery sampah. Tujuannya untuk mengetahui pengaruh recycle dan recovery sampah perkotaan terhadap jumlah sampah yang masuk ke TPA sampah Cipayung Depok. Salah satu langkah untuk membentuk MFA adalah mendefinisikan suatu kondisi eksisting untuk menilai perkembangan di masa depan. Pada kasus ini, dibuat model untuk periode satu tahun yang dimulai pada tahun 2017 hingga 2018.

Software MFA STAN (The STANdard for Material Flow Analysis) merupakan perangkat gratis yang dapat membantu menampilkan analisa aliran material berdasarkan standar Austria ÖNorm S 2096 (aplikasi-analisa aliran material di dalam pengelolaan sampah). Komponen untuk membangun model MFA terdiri dari sistem batas, proses, dan aliran.

\section{$\checkmark$ Sistem Batas}

Data yang akan diperhitungkan harus didefinisikan dalam ruang dan waktu. Sstem batas ruang misalnya perbatasan logistik suatu perusahaan atau perbatasan spasial suatu daerah, sedangkan sistem batas waktu misalnya waktu keseimbangan untuk satu tahun.

$\checkmark$ Proses

Untuk model, hanya proses-proses yang diperhitungkan yang terletak dalam sistem batas, dimana menggunakan hukum kekekalan massa. Proses di luar batas sistem tidak diperhitungkan. Proses bisa terdapat stok atau subsistem yang dapat dijelaskan oleh model tambahan.

$\checkmark$ Aliran

Terdapat aliran impor/input (aliran internal yang menghubungkan proses ke dalam sistem) dan aliran ekspor/output (aliran yang melintasi sistem batas).

\section{Perhitungan Model MFA STAN}

Untuk menggambarkan model dengan cara matematika, terdapat 3 jenis persamaan utama yang digunakan (persamaan kesetimbangan).

$\checkmark$ Kekekalan Massa

Persamaan matematika kekekalan massa digunakan untuk persamaan kesetimbangan dan stok.

Persamaan kesetimbangan:

$\sum$ Input $=\sum$ Output + Perubahan di dalam stok

Persamaan stok:

Sto $_{\mathrm{i}}=$ Stok $_{\mathrm{i}-1}+$ perubahan didalam stok $\mathrm{k}_{\mathrm{i}-1}$

Keterangan:

stok $_{i}=$ stok $_{i-1}+$ perubahan di dalam stok $_{i-1} ;$ i merupakan periode

Jumlah stok pada awal periode dapat dihitung dari jumlah stok dalam periode sebelumnya ditambah perubahan stok selama periode sebelumnya. Namun, stok adakalanya bernilai nol (tidak diperhitungkan)

\section{Hubungan Linear}


Persamaan matematika yang menyatakan hubungan linear, misalnya persamaan koefisien transfer.

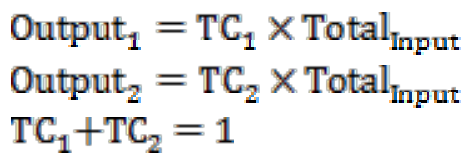

MFA STAN memungkinkan pertimbangan untuk ketidakpastian data (data uncertainty). Diasumsikan bahwa jumlah yang tidak pasti terdistribusi secara normal, yang diberikan oleh nilai rata-rata dan standar deviasi. Pendekatan ini menawarkan kemungkinan untuk menggunakan metode seperti propagasi kesalahan (error propagation) dan rekonsiliasi data (data reconciliation). Misalnya jumlah yang acak terdistribusi secara normal dengan nilai rata-rata 100 dan standar deviasi 20.95 persen dari semua data dapat ditemukan dalam interval nilai rata-rata + / - dua kali standar deviasi, sehingga disebut interval kepercayaan $95 \%$.

\section{Hasil dan Pembahasan}

Kondisi eksisting sistem pengelolaan sampah di TPA sampah Cipayung, Depok masih berupa kegiatan penerimaan, pencatatan, penataan dan pemadatan sampah di kolam sampah TPA Cipayung yang sedang aktif digunakan. Sehingga sampah masih sangat banyak yang belum diberdayakan. Selain itu juga diketahui karaketristik sampah (fisik dan kimia), komposisi, laju pengangkutan dan laju pengumpulan sampah ke TPA Cipayung sebagai berikut.

- Karakteristik fisik sampah di TPA Cipayung adalah berat jenis sampah TPA Cipayung 220,44 $\mathrm{kg} / \mathrm{m}^{3}$. Untuk ukuran partikel sampah TPA Cipayung, Ø>50 mm sebanyak $62,875 \%, 10 \mathrm{~mm}<\varnothing$ $<50 \mathrm{~mm}$ sebanyak 30,606\%, dan $\varnothing<10 \mathrm{~mm}$ sebanyak 6,519\%. Sedangkan kadar air sampah di TPA Cipayung untuk jenis sampah organik 70,704\%, kayu 26,894\%, tekstil 26,181\%, kertas $21,126 \%$, plastik $19,895 \%$, lain-lain 16,448\%, serta karet dan kulit 12,514\%. Sedangkan komposisi sampah TPA Cipayung dan yang dapat dijual oleh pemulung terlihat pada gambar 3 dan 4.

\section{Komposisi Sampah TPA Cipayung}

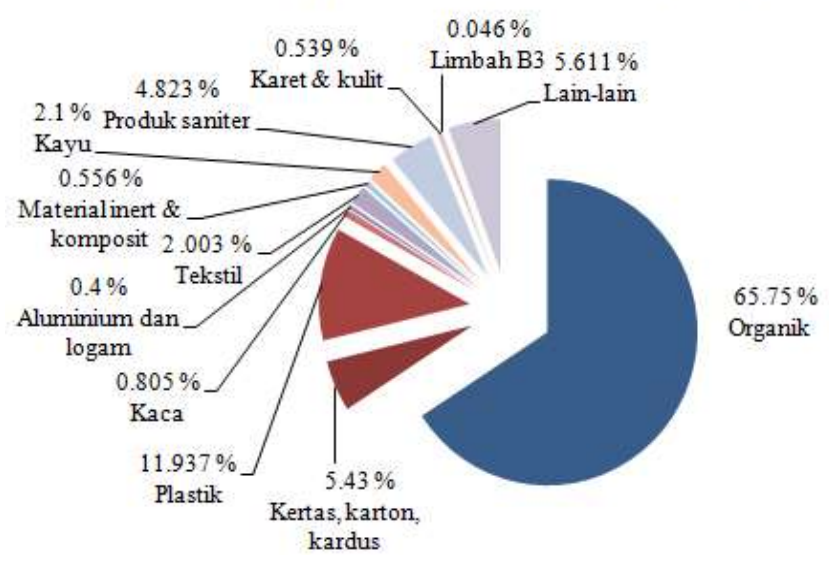

Gambar 3: Komposisi Sampah TPA Cipayung

- Karakteristik kimia sampah di TPA Cipayung adalah kadar volatil sampah kertas, karton dan kardus $(68,481 \%)$, plastik $(66,093 \%)$, lain-lain $(63,601 \%)$, karet dan kulit $(63,566 \%)$, kayu $(56,719 \%)$, tekstil $(47,491 \%)$, dan organik $(22,666 \%)$. Untuk kadar abu sampah TPA Cipayung adalah organik $(2,073 \%)$, kertas, kardus dan karton (5,563\%), lain-lain (8,459\%), kayu (10,291\%), plastik (10,6075\%), karet dan kulit (15,545\%), dan tekstil (19,946\%). Sedangkan untuk kadar karbon (C) sampah organik TPA Cipayung adalah 40,068\%, nitrogen $(\mathrm{N})$ sebesar 1,529\% dan C:N sebesar 26,119:1. Untuk nilai kalor sampah yang mudah terbakar di TPA Cipayung adalah 2.755,63$6.552,25 \mathrm{kCal} / \mathrm{kg}$. 


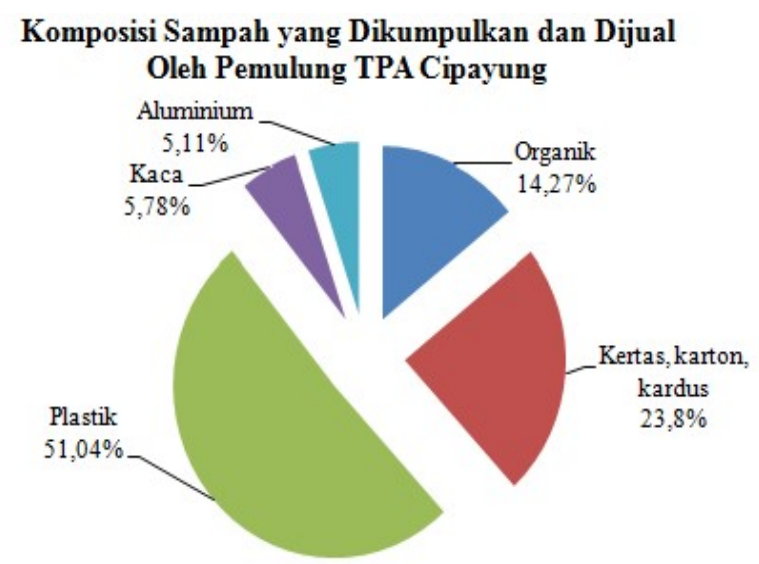

Gambar 4: Komposisi Sampah yang Dikumpulkan dan Dijual

Pemulung dari Kolam Sampah TPA Cipayung

Berdasarkan karakteristik fisik dan kimia, sampah di TPA Cipayung berpotensi untuk teknologi daur ulang, pengomposan dan bahan baku Refused Derived Fuel/RDF. Sampah yang berpotensi didaur ulang adalah sebesar $25,417 \%$, untuk pengomposan sebesar $58,906 \%$ dan untuk RDF sebesar $27,619 \%$. Persentase tersebut adalah potensi sampah berdasarkan komposisinya dengan menganggap bahwa masing-masing komposisi sampah tersebut dapat berpotensi seluruhnya bila diasumsikan akan diolah melalui penerapan teknologi tersebut. Khusus sebagai bahan baku RDF, maka perlu dilakukan pra pengolahan untuk menurunkan kadar air sampah karena didominasi oleh sampah organik yang memiliki kadar air tinggi.

- Laju pengangkutan sampah kota Depok ke TPA Cipayung $=217$ ton/hari, laju pengumpulan sampah kota Depok ke TPA $=0,52$ lt/orang/hari atau $0,11 \mathrm{~kg} / \mathrm{orang} / \mathrm{hari}$ dan tingkat layan pengangkutan sampah ke TPA Cipayung adalah 19,57\%. Berdasarkan perhitungan yang melibatkan data jumlah penduduk, diperoleh hasil proyeksi laju pengangkutan sampah kota Depok ke TPA Cipayung dan digunakan untuk nilai input ke model MFA STAN.

Tabel 2: Laju Pengangkutan Sampah Kota Depok ke TPA Cipayung

\begin{tabular}{|l|l|l|l|l|l|l|l|}
\hline \multirow{2}{*}{ No } & \multirow{2}{*}{ Tahun } & $\begin{array}{c}\text { Jumlah } \\
\text { Penduduk } \\
\text { (Jiwa) }\end{array}$ & $\begin{array}{c}\text { TPA Cipayung } \\
\text { (lt/hari) }\end{array}$ & $\begin{array}{c}\text { TPA } \\
\text { Cipayung } \\
\left(\mathrm{m}^{3} / \text { hari) }\right.\end{array}$ & $\begin{array}{c}\text { TPA } \\
\text { Cipayung } \\
\text { (ton/hari) }\end{array}$ & $\begin{array}{c}\text { TPA } \\
\text { Cipayung } \\
\left(\mathrm{m}^{3} / \text { tahun) }\right.\end{array}$ & $\begin{array}{c}\text { TPA } \\
\text { Cipayung } \\
\text { (ton/tahun) }\end{array}$ \\
\hline 1 & 2006 & 1.420 .480 & $738.649,6$ & 738,650 & 162,828 & $203.867,290$ & $44.940,505$ \\
\hline 2 & 2007 & 1.470 .002 & $764.401,04$ & 764,401 & 168,505 & $210.974,687$ & $46.507,26$ \\
\hline 3 & 2008 & 1.503 .677 & $781.912,04$ & 781,912 & 172,365 & $215.807,723$ & $47.572,655$ \\
\hline 4 & 2009 & 1.536 .980 & $799.229,6$ & 799,230 & 176,182 & $220.587,370$ & $48.626,280$ \\
\hline 5 & 2010 & 1.736 .565 & $903.013,8$ & 903,014 & 199,060 & $249.231,809$ & $54.940,660$ \\
\hline 6 & 2011 & 1.815 .373 & $943.994,189$ & 943,994 & 208,094 & $260.542,396$ & $57.433,966$ \\
\hline 7 & 2012 & 1.894 .352 & $985.063,107$ & 985,063 & 217,147 & $271.877,417$ & $59.932,658$ \\
\hline 8 & 2013 & 1.973 .331 & $1.026 .132,024$ & $1.026,132$ & 226,201 & $283.212,439$ & $62.431,35$ \\
\hline 9 & 2014 & 2.052 .310 & $1.067 .200,942$ & $1.067,201$ & 235,254 & $294.547,46$ & $64.930,042$ \\
\hline 10 & 2015 & 2.131 .288 & $1.108 .269,86$ & $1.108,270$ & 244,307 & $305.882,481$ & $67.428,734$ \\
\hline 11 & 2016 & 2.210 .267 & $1.149 .338,778$ & $1.149,339$ & 253,360 & $317.217,503$ & $69.927,426$ \\
\hline $\mathbf{1 2}$ & $\mathbf{2 0 1 7}$ & $\mathbf{2 . 2 8 9 . 2 4 6}$ & $\mathbf{1 . 1 9 0 . 4 0 7 , 6 9 5}$ & $\mathbf{1 . 1 9 0 , 4 0 8}$ & $\mathbf{2 6 2 , 4 1 3}$ & $\mathbf{3 2 8 . 5 5 2 , 5 2 4}$ & $\mathbf{7 2 . 4 2 6 , 1 1 8}$ \\
\hline $\mathbf{1 3}$ & $\mathbf{2 0 1 8}$ & $\mathbf{2 . 3 6 8 . 2 2 4}$ & $\mathbf{1 . 2 3 1 . 4 7 6 , 6 1 3}$ & $\mathbf{1 . 2 3 1 , 4 7 7}$ & $\mathbf{2 7 1 , 4 6 7}$ & $\mathbf{3 3 9 . 8 8 7 , 5 4 5}$ & $\mathbf{7 4 . 9 2 4 , 8 1 1}$ \\
\hline
\end{tabular}

Rancangan skenario model MFA STAN dilakukan melalui modifikasi dan perbaikan dari kondisi eksisting sehingga diketahui pengelolaan terbaik untuk mereduksi sampah yang akan ditimbun ke TPA sampah, menjadi sumber daya (untuk mengetahui potensi recycle dan recovery) serta yang dapat memperpanjang umur layan TPA Cipayung (tabel 3). 
Tabel 3: Rancangan Modelisasi MFA STAN Sistem TPA Cipayung Berdasarkan Kondisi Eksisting dan Skenario 1

\begin{tabular}{|c|c|c|c|c|c|}
\hline 0 & Model & $\begin{array}{l}\text { Teknologi } \\
\text { Pengolah } \\
\text { Sampah }\end{array}$ & $\begin{array}{l}\text { Kolam } \\
\text { Sampah B }\end{array}$ & $\begin{array}{l}\text { UPS } \\
\text { Hanggar }\end{array}$ & Keterangan \\
\hline \multirow{4}{*}{1} & \multirow{4}{*}{ Eksisting } & Komposting & - & $4,5 \%$ & $\begin{array}{l}\text { Berpotensi untuk optimalisasi input sampah ke UPS } \\
\text { Hanggar dan penambahan jumlah UPS (DKP, 2009) }\end{array}$ \\
\hline & & Daur Ulang & $3,07 \%$ & $0,75 \%$ & $\begin{array}{l}\text { Berpotensi adanya peningkatan jumlah pemulung } \\
\text { (diasumsikan meningkat 5\%/tahun) yang akan } \\
\text { meningkatkan pemilahan di kolam sampah (DKP, 2009) }\end{array}$ \\
\hline & & $\mathrm{RDF}$ & - & - & $\begin{array}{l}\text { Berpotensi pemberdayaan sampah di kolam sampah } \\
\text { sebagai bahan baku RDF }\end{array}$ \\
\hline & & $\begin{array}{l}\text { Penimbunan } \\
\text { Akhir }\end{array}$ & \multicolumn{2}{|c|}{$91,68 \%$} & $\begin{array}{l}\text { Berpotensi adanya penurunan tingkat pembuangan } \\
\text { sampah untuk ditimbun }\end{array}$ \\
\hline \multirow[t]{4}{*}{4} & \multirow[t]{4}{*}{ Skenario 1} & Komposting & - & $11,81 \%$ & $\begin{array}{l}\text { Optimalisasi kapasitas UPS Hanggar (input sampah } \\
\text { mencapai } 30 \mathrm{~m}^{3} / \text { hari/UPS), penambahan jumlah UPS } \\
\text { sebanyak } 7-8 \text { UPS untuk kurun waktu } 2014-2019 \text { dan } \\
\text { pengaturan pola pengangkutan ke UPS Hanggar sebesar } \\
\text { 20\% (PERATURAN MENTERI PEKERJAAN UMUM } \\
\text { NOMOR: 21/PRT/M/2006) }\end{array}$ \\
\hline & & Daur Ulang & $3,21 \%$ & $1,97 \%$ & Peningkatan jumlah pemulung, asumsi $10 \% /$ tahun \\
\hline & & $\mathrm{RDF}$ & $19,78 \%$ & - & $\begin{array}{l}\text { Pemberdayaan potensi sampah menjadi bahan baku RDF } \\
\text { (sampah selain setelah hasil pemilahan oleh pemulung) }\end{array}$ \\
\hline & & $\begin{array}{l}\text { Penimbunan } \\
\text { Akhir }\end{array}$ & \multicolumn{2}{|c|}{$63,23 \%$} & Penurunan tingkat pembuangan sampah untuk ditimbun \\
\hline
\end{tabular}

Hasil model MFA STAN untuk periode 2017-2018 dapat dilihat pada gambar 5 hingga gambar 12 dan secara ringkas pada tabel 4 . Terlihat bahwa skenario 1 mampu mereduksi hampir lebih dari 50\% sampah yang akan ditimbun melalui pemanfaatan sampah berdasarkan potensi sampah sebagai bahan baku untuk daur ulang, kompos, dan RDF. Bila efisiensi pemilahan sampah ditingkatkan melalui alat mekanik untuk memilah sampah yang masuk ke TPA Cipayung, maka langkah untuk optimasi skenario 1 akan dapat mengurangi sampah perkotaan yang akan ditimbun secara signifikan hingga mencapai kondisi zero waste.

Tabel 4: Ringkasan Hasil Model MFA STAN Tahun 2017-2018

\begin{tabular}{|c|c|c|c|c|c|c|c|c|c|}
\hline \multirow{4}{*}{ Tahun } & \multirow{4}{*}{ Kondisi } & \multirow{4}{*}{$\begin{array}{c}\text { Input ke } \\
\text { sistem batas } \\
\text { TPA } \\
\text { Cipayung } \\
\text { Berat sampah } \\
\text { yang masuk } \\
\text { (ton/tahun) }\end{array}$} & \multicolumn{6}{|c|}{ Input ke sub sistem batas TPA Cipayung } & \multirow{4}{*}{$\begin{array}{c}\text { Output dari } \\
\text { sistem batas } \\
\text { TPA } \\
\text { Cipayung } \\
\text { Residu ke } \\
\text { kolam } \\
\text { sampah } \\
\text { (ton/tahun) }\end{array}$} \\
\hline & & & \multicolumn{3}{|c|}{ Kolam sampah } & \multicolumn{3}{|c|}{ UPS Hanggar TPA } & \\
\hline & & & Input & \multicolumn{2}{|c|}{ Output } & Input & \multicolumn{2}{|c|}{ Output } & \\
\hline & & & $\begin{array}{c}\text { Berat sampah } \\
\text { yang masuk } \\
\text { (ton/tahun) }\end{array}$ & $\begin{array}{l}\text { Bahan baku } \\
\text { daur ulang } \\
\text { (ton/tahun) }\end{array}$ & $\begin{array}{c}\text { Bahan baku } \\
\text { RDF } \\
\text { (ton/tahun) }\end{array}$ & $\begin{array}{c}\text { Berat } \\
\text { sampah yang } \\
\text { masuk } \\
\text { (ton/tahun) }\end{array}$ & $\begin{array}{c}\text { Bahan baku } \\
\text { kompos } \\
\text { (ton/tahun) }\end{array}$ & $\begin{array}{l}\text { Bahan baku } \\
\text { daur ulang } \\
\text { (ton/tahun) }\end{array}$ & \\
\hline \multirow{2}{*}{2017} & Eksisting & 72426,118 & 67558,803 & 2297,40 & - & 4867,32 & 2920,389 & 486,732 & 66721,601 \\
\hline & Skenario 1 & 72426,118 & 57824,173 & 2650,84 & 13987,15 & 14601,95 & 8761,167 & 1460,195 & 45566,766 \\
\hline \multirow{2}{*}{2018} & Eksisting & 74924,810 & 70057,495 & 2398,38 & - & 4867,32 & 2920,389 & 486,732 & 69119,309 \\
\hline & Skenario 1 & 74924,810 & 60322,865 & 2840,19 & 14535,58 & 14601,95 & 8761,167 & 1460,195 & 47327,680 \\
\hline
\end{tabular}




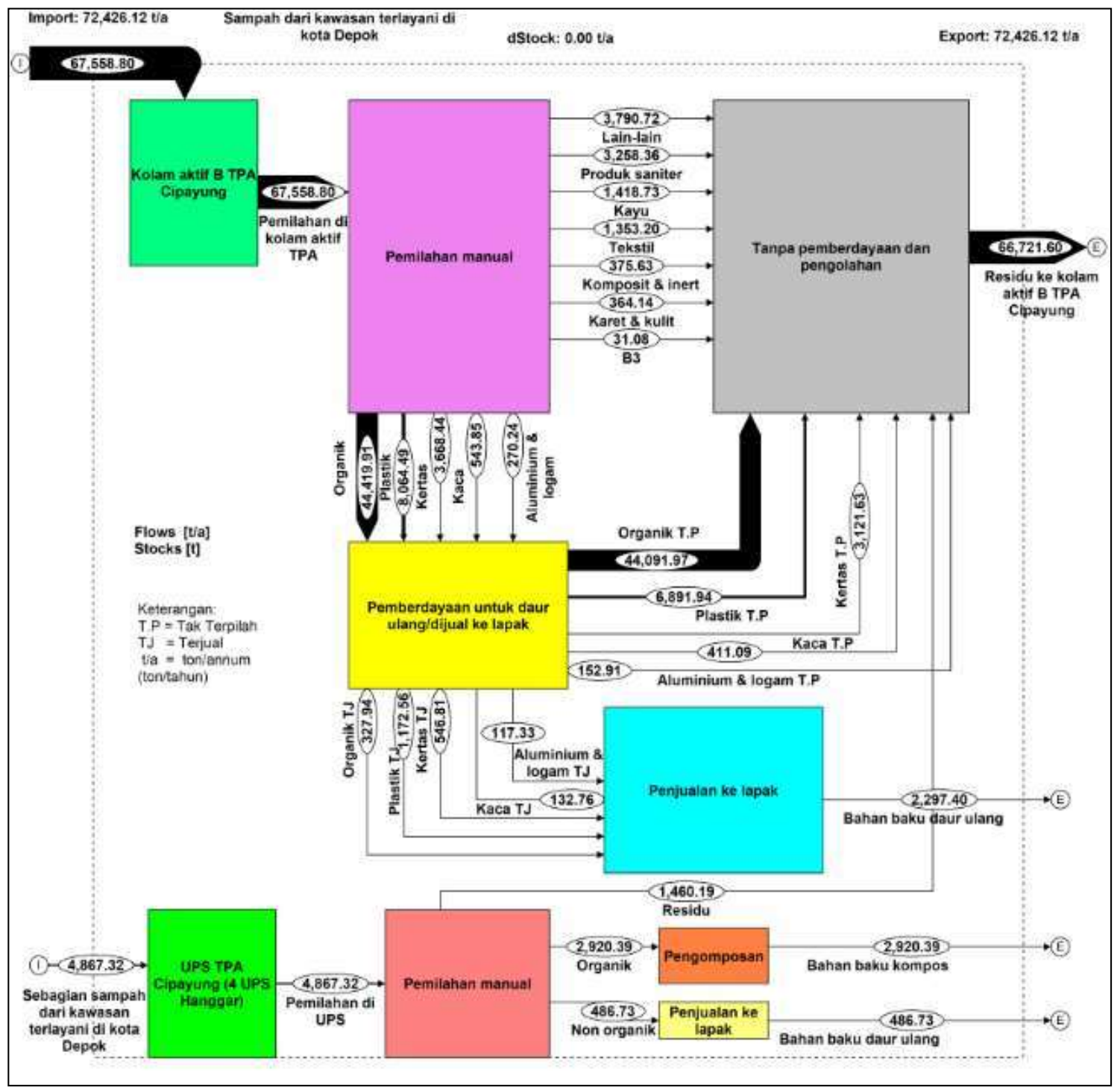

Gambar 5: Model MFA STAN TPA Cipayung Eksisting 2017

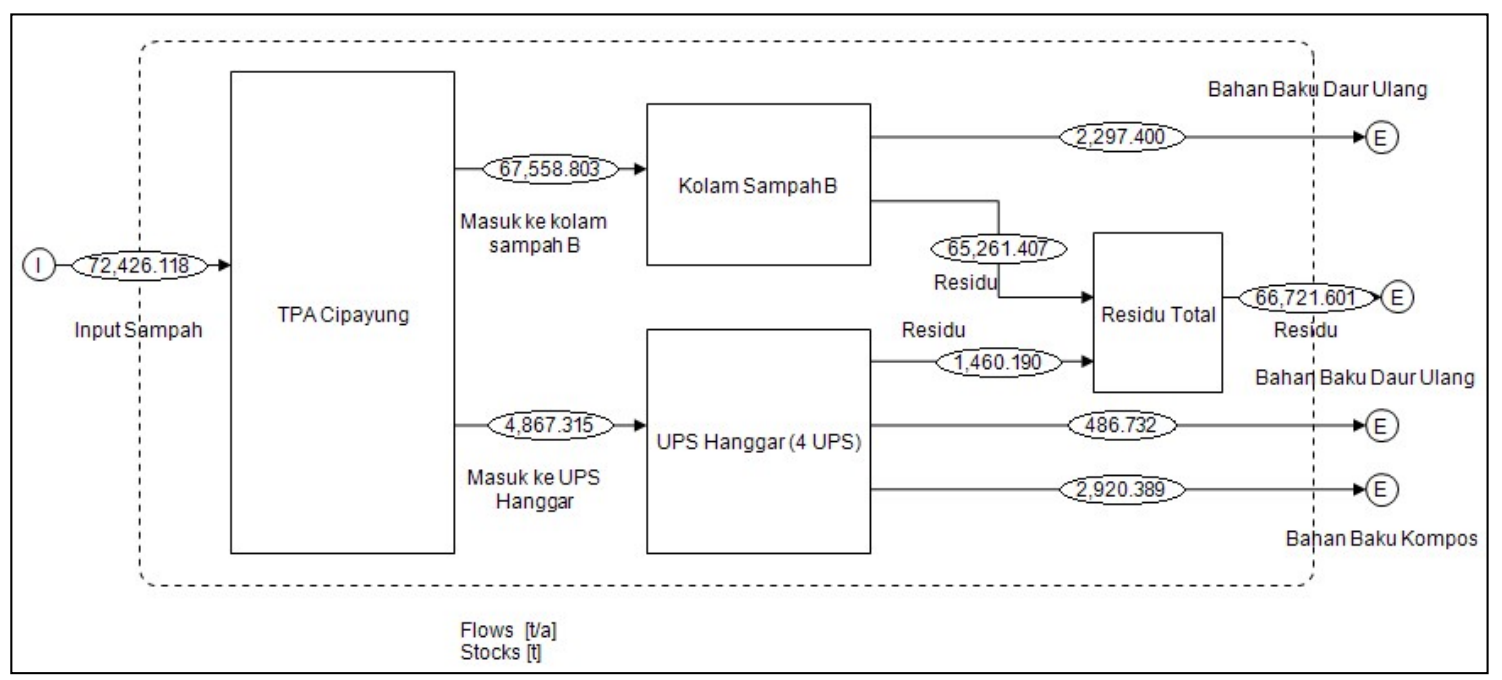

Gambar 6: Ringkasan Model MFA STAN TPA Cipayung Eksisting 2017 


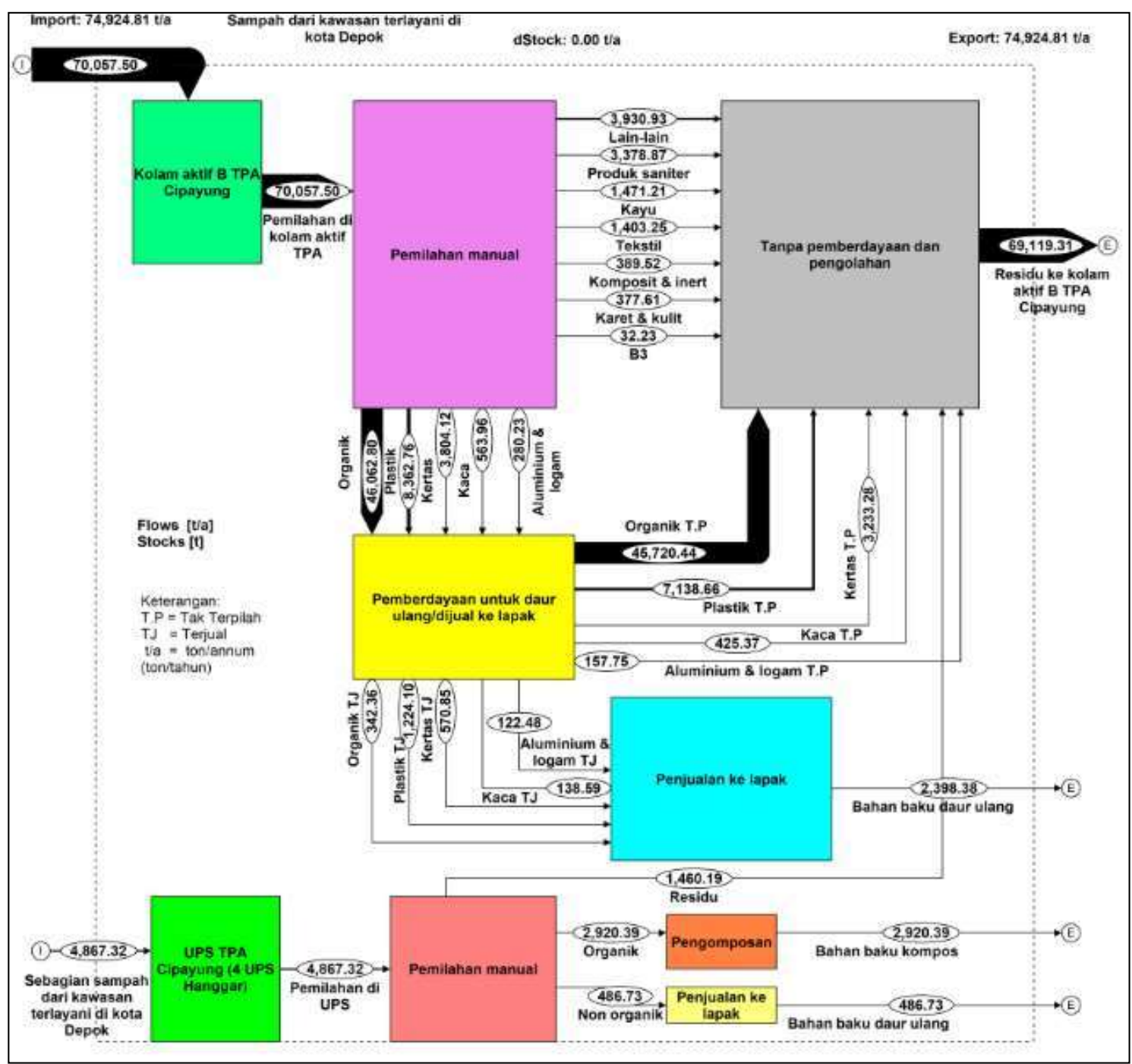

Gambar 7: Model MFA STAN TPA Cipayung Eksisting 2018

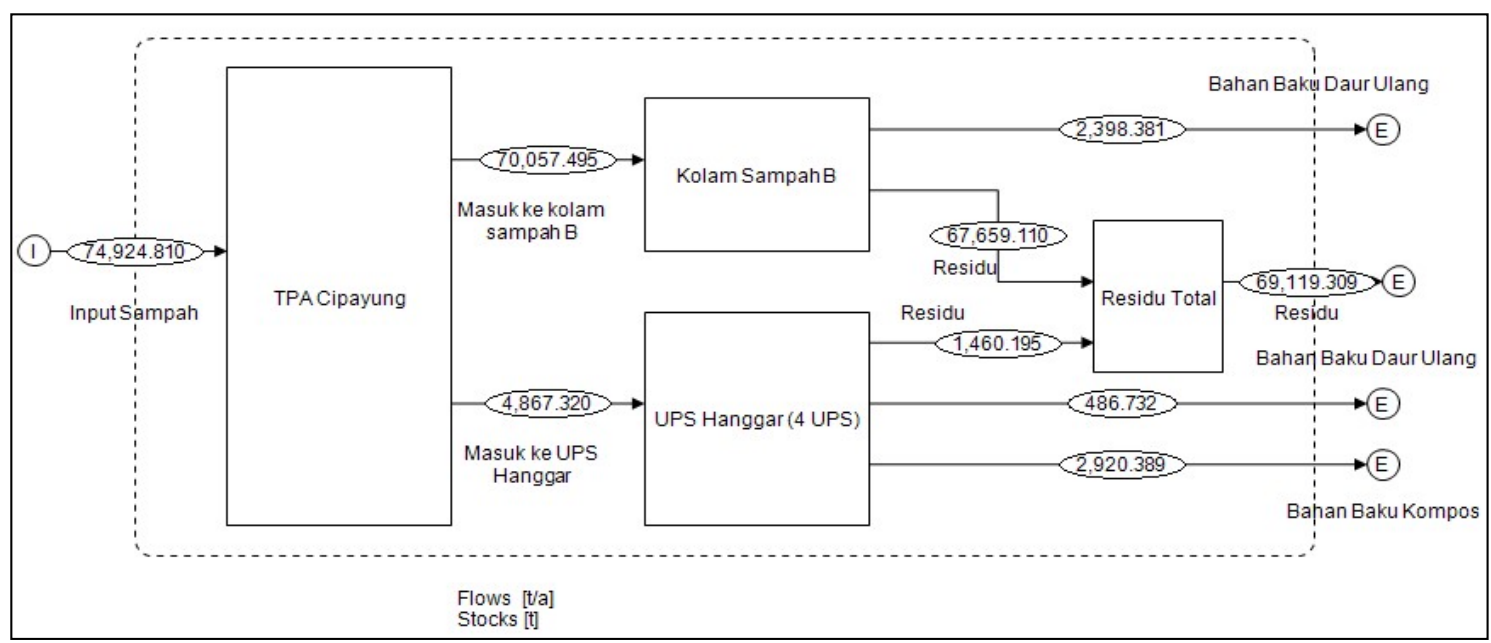

Gambar 8: Ringkasan Model MFA STAN TPA Cipayung Eksisting 2018 


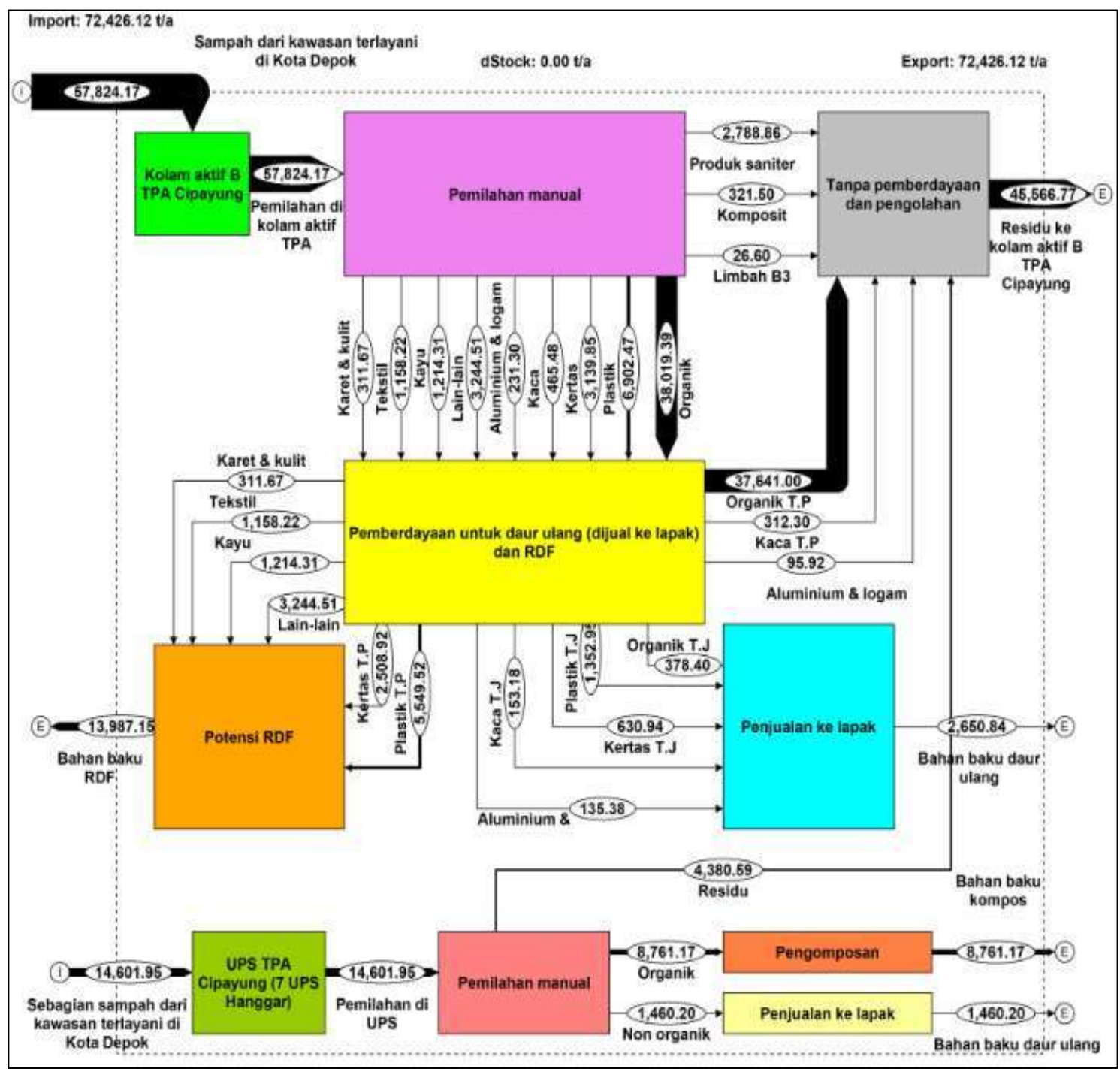

Gambar 9: Model MFA STAN TPA Cipayung Skenario 2017

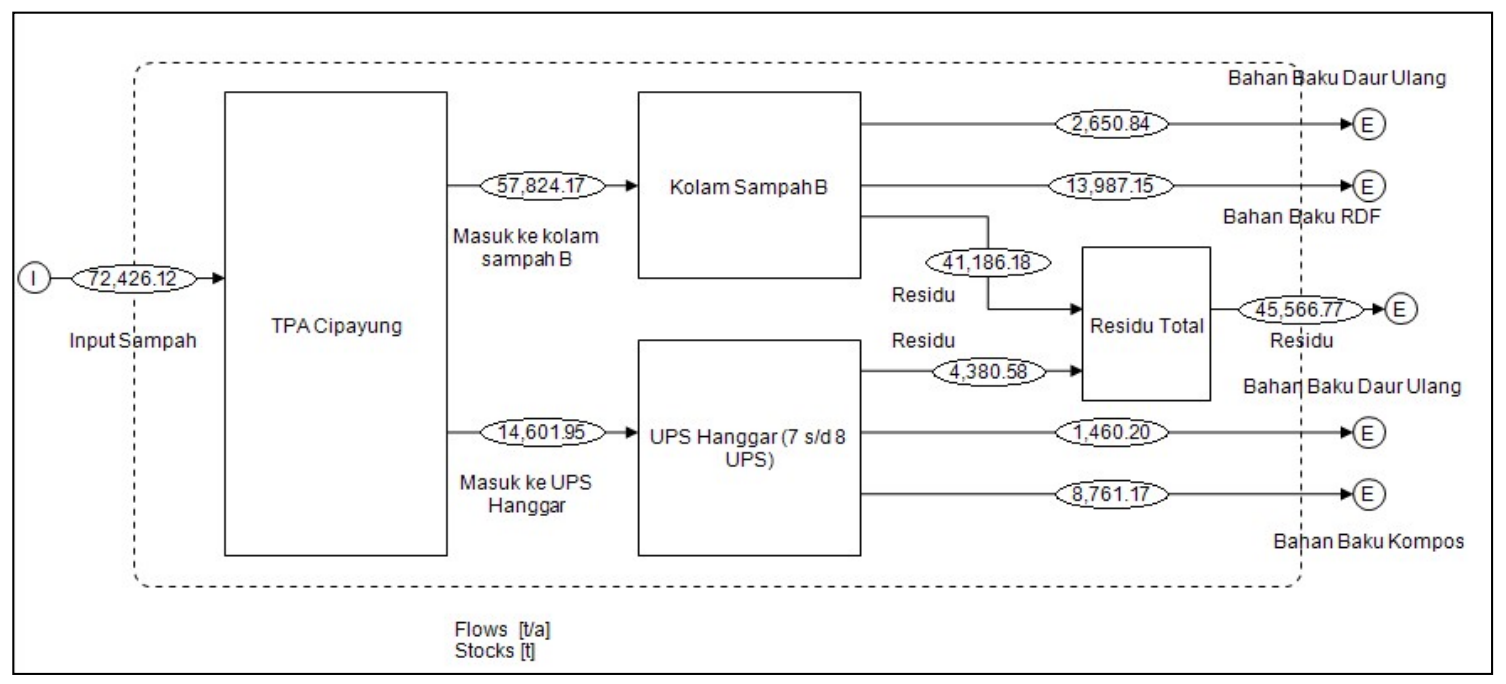

Gambar 10: Ringkasan Model MFA STAN TPA Cipayung Skenario 2017 


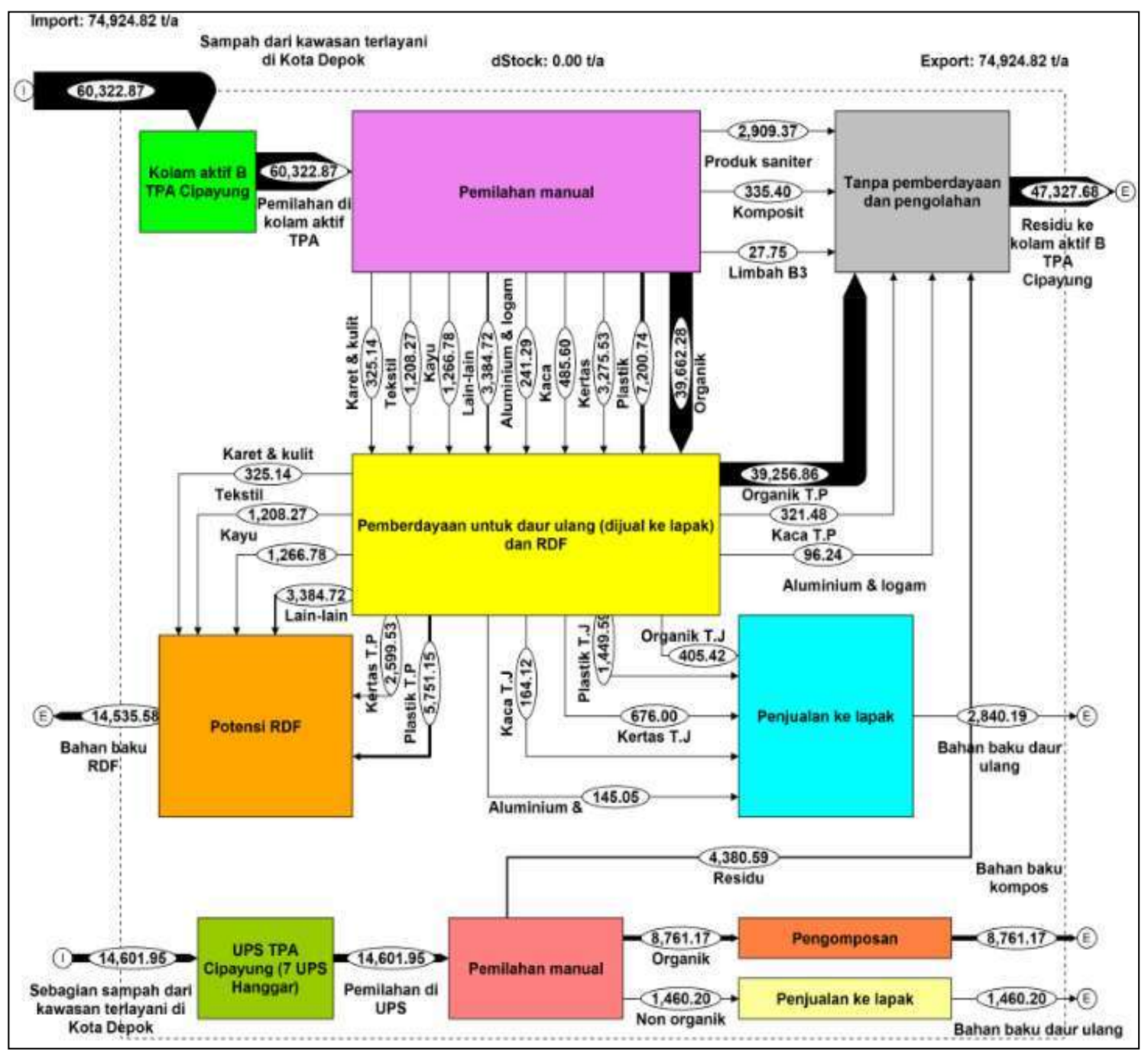

Gambar 11: Model MFA STAN TPA Cipayung Skenario 2018

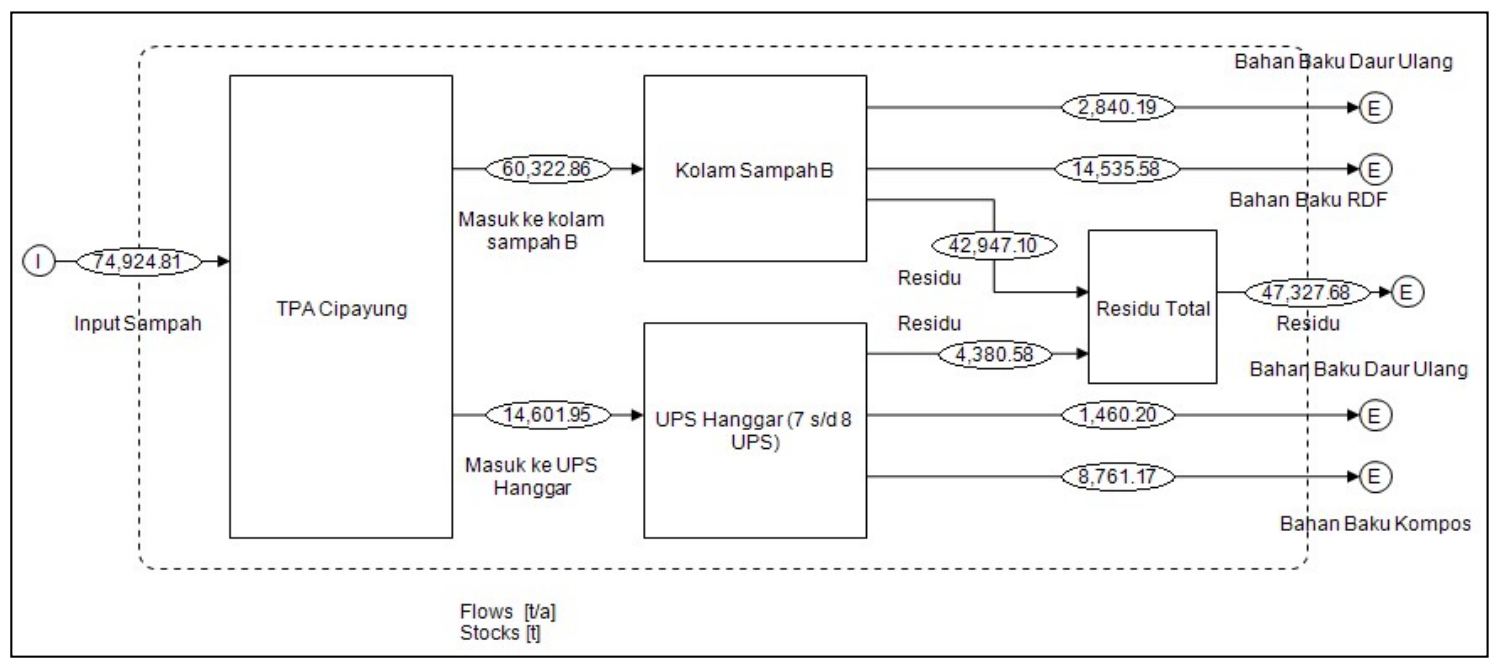

Gambar 12 : Ringkasan Model MFA STAN TPA Cipayung Skenario 2018 


\section{Kesimpulan}

1. Aliran kritis sistem pengelolaan sampah terdapat pada proses pemilahan dan pemberdayaan yang masih secara manual, sehingga berdampak kepada besarnya sampah residu yang akan ditimbun di TPA sampah Cipayung.

2. Komposisi sampah yang termasuk pada aliran kritis adalah sampah organik, plastik, kertas, kaca dan aluminium. Semua material yang berada pada aliran kritis masih dapat diberdayakan dengan menggunakan mesin mekanik pemilah sampah.

3. Rekomendasi pengelolaan sampah di TPA adalah dengan menerapkan teknologi daur ulang, pengomposan dan bahan baku RDF.

4. Pemerintah sebaiknya menjalin kerjasama dengan pihak swasta untuk mengolah sampah menjadi sumber daya sehingga memperpanjang umur layan TPA sampah.

5. Melalui optimasi skenario 1, maka aliran kritis sistem pengelolaan sampah dapat diperbaiki dengan pengurangan lebih dari 50\% sampah yang akan ditimbun ke TPA sampah Cipayung.

\section{Daftar Pustaka}

Andersen, J.K., Boldrin, A., Christensen, T.H., Scheutz, C. (2011). Mass balances and life cycle inventory of home composting of organic waste. Journal of Waste Management, 31 (2011) 1934-1942. January 30, 2012. http://www.sciencedirect.com/science/article/pii/S0956053X11002248

Annisa, Bismi. (2013). Pengaruh Recycle dan Recovery Sampah terhadap Jumlah Sampah yang Masuk ke TPA Cipayung, Depok dengan Menggunakan Model MFA (Material Flow Analysis). Tesis, Program Magister Teknik Sipil Universitas Indonesia, Depok.

Annisa, Bismi. (2016). Scenarios Tackling Municipal Solid Waste (MSW) Flow Into Landfill Based On MFASTAN Integrative Method Towards Building Sustainable City In Indonesia. Paper presented at the $2^{\text {nd }}$ International Conference on Civil Engineering Research (ICCER), Surabaya.

Badan Standardisasi Nasional (BSN). (1994). SNI 19-3964-1994: Standar Nasional Indonesia untuk metode pengambilan dan pengukuran contoh timbulan dan komposisi sampah perkotaan. Jakarta: Author.

Cencic, O., Rechberger, H. (2008). Material Flow Analysis with Software STAN. Journal of Environmental Engineering Management, 18 (1) 2008: 3-7.

Dinas Kebersihan dan Pertamanan (DKP) Kota Depok. (2009). Laporan akhir: kajian rencana optimalisasi pengelolaan TPA Cipayung Kota Depok. Jakarta: Nusa Buana Cipta.

Dinas Kebersihan dan Pertamanan (DKP) Kota Depok. (2011). Presentasi: Profil Dinas Kebersihan dan Pertamanan Kota Depok tahun 2011. Depok: Author.

Kurniawati, Nia. "Studi Timbulan dan Komposisi Limbah Padat di Tempat Pembuangan Akhir Cipayung sebagai Dasar Perhitungan Periode Aktif Tempat Pembuangan Akhir”. Skripsi, Program Sarjana Fakultas Teknik UI, Depok, 2010.

Pires, A., Martinho, G., Ni-Bin Chang. (2011). Solid waste management in European countries: A review of systems analysis techniques. Journal of Environmental Management, 92 (2011), 1033-1050. May 15, 2011. http://www.sciencedirect.com/science/article/pii/S0301479710004275

Zaman, A.U., Lehmann, S. (2011). Urban growth and waste management optimization towards 'zero waste city'. Journal of City, Culture and Society in Press, 2 (2011) 177-187. January 26, 2012.

http://www.sciencedirect.com/science/article/pii/S1877916611000786 